\title{
Predictors of Workplace Well-Being for Dual-Earner Couples During Covid-19 Pandemic
}

\author{
Gisela Oktaria Efi ${ }^{1}$, Endang Parahyanti ${ }^{2}$ \\ ${ }^{1,2}$ Faculty of Psychology, Universitas Indonesia
}

\begin{abstract}
The Covid-19 pandemic has changed the life order of entire community including employees from dual-earner families. Overlapping roles experienced can cause tension and trigger work-family conflicts that can impact workplace well-being. Previous studies had often focused on well-being in general and there was a lack of research related to well-being in dual earner couples during pandemic. This study investigated the predictor role of core selfevaluation and spousal support through mediating role of work family conflict (WFC) on workplace well-being. Based on the conservation of resources theory, we need to identify essential resource to fulfill workplace well-being. Data were collected from 200 employed Jakarta Metropolitan area (Jabodetabek) dual-earners who had at least one child below the age of 13 . According to the mediation with two predictors analysis, the mediating effect of WFC can only predict the linkage between core self-evaluation and workplace well-being $(\beta=0.02, S E=0.02$; $95 \%$ CI $[0.005,0.061])$ but cannot predict the role of spousal support through WFC on workplace well-being ( $\beta=0.00, S E=0.00 ; 95 \%$ CI $[-0.002,0.007])$. This finding explained the importance of self-evaluation during pandemic to enhance workplace well-being and buffered negative effect of work and family related burdens.
\end{abstract}

Keywords: core self-evaluation; dual earner couple; spousal support; work family conflict; workplace well-being

Currently, the world is shaken by the Covid-19 pandemic. The unpredictable pandemic situation where someone has low control over that situation can be a threat to the individual's well-being (Taha et al., 2014). The large scale social restriction policy (Pembatasan Sosial Berskala Besar/PSBB) applied during this pandemic era causes negative effects on a person's psychological aspects; e.g.: stress due to minimum social contact, loss of freedom, boredom, and even leading to depression symptoms (Lunn et al., 2020; Zhang \& Ma, 2020). According to a research finding from Iskandarsyah and Yudiana (2020) about psychological condition and perception towards Covid-19 in Indonesia, people who live in Jakarta, Banten, and West Java have a higher level of anxiety and perceive that the risk of transmission is higher than the other regions in Indonesia.

The pandemic presents novel and unique challenges for a person in maintaining their well-being, facing employment and career uncertainties, as well as dealing with familywork roles (Restubog et al., 2020). The implementation of a work from home system can cause a worker to spend longer working hours which potentially increases conflict within the family (Baruch, 2000; Maruyama \& Tietze, 2012). Employees who still need to be in- 
office have to deal with the possible virus transmission while being out of the house. Threats to one's well-being can be a source of despair especially when the threats are inexplicable, uncertain, ambiguous, and when the person thinks that they have low control over the stressor (Taha et al., 2014). In addition, to adapt to the new work pattern, employees who are raising school-age children also have to accompany their children as well as being fully responsible for child-rearing. For dual-earner couples, work responsibilities must be fulfilled alongside their domestic tasks. It causes the line between work and personal domains to be more blurred during this pandemic. Various role demands that must be faced altogether become a threat to one's well-being.

Well-being is generally divided into two perspectives namely hedonic which focuses on the presence of positive affect, the lack of negative affect, and cognitive evaluation of individual's life satisfaction as well as eudaimonic which focuses on the fulfillment of one's potentials through self-actualization, meaningfulness, and personal development (Deci \& Ryan, 2008; Fisher, 2014; Ryan \& Deci, 2001). Hobfoll $(1989,2002)$ explained that when someone is experiencing an increase of resources, they will experience positive well-being while when the person is unable to obtain resources then they will experience stress and lack of well-being. Rothausen (2013) said that resources can be categorized into primary and secondary resources. Primary resources encompass self-esteem, mastery, intimacy, protection, and self-improvement (Hobfoll, 1989, 2002). This is aligned with the aspects of psychological well-being that are eudaimonic-oriented, namely self-acceptance, environmental mastery, positive relationships, autonomy, life purpose, and personal growth (Ryff, 1989). Secondary resources help someone to achieve the primary resources (Rothausen, 2013) and it can include objects, relations, conditions, and personal characteristics that serve as the means to an end (Hobfoll, 1989, 2002). In line with that, Santrock (2011) described that family and work are the two main domains that become an adult's focus. Thus, the measurement of well-being particularly for adults needs to incorporate the two domains to be more comprehensive.

Zheng et al. (2015) introduced a more contextual employee well-being concept for workplace situations compared to other general well-being concepts. The measurement of well-being in a specific context is needed to capture the details, complexities, and variations of an employee's cognitive and affective experiences at the workplace. Moreover, the employee well-being concept developed by Zheng et al. (2015) is oriented to the Eastern culture which has a difference from the well-being concept applied in Western culture. Specifically, the Western culture emphasizes environmental mastery, autonomy, and personal emotions in well-being. On the other hand, Eastern culture emphasizes harmony and social values in achieving a higher level of well-being (Zheng et al., 2015). The concept of employee well-being is also a combination of hedonic and eudaimonic perspectives that measures both satisfaction in life and employment as well as aspects of psychological well-being at the workplace. The measurement of employee 
well-being should not only consider the work and health of an employee but also measure their familial relationship and life satisfaction (Zheng et al., 2015).

Zheng et al. (2015) stated that employee well-being involves not only employee perception and feeling about their work and life satisfaction but alson their psychological experience and the level of satisfaction exhibited in both their work and personal lives. Employee well-being is construed of three components, i.e.: life well-being (LWB) which focuses on personal emotion reflection, life problems, and family; workplace well-being (WWB) that includes aspects related to work such as compensation and benefits, employment protection, managerial style, and the work arrangements; as well as psychological well-being (PWB) that emphasizes learning, personal development, work achievements, and self-actualization (Zheng et al., 2015).

The present study would deeply explore the predictive factors needed to achieve workplace well-being (WWB) that encompass job satisfaction and things affecting work (Zheng et al., 2015) amidst the pandemic. The shift in work arrangement and the unpredictable economic situation can have impacts on job continuity. Covid-19 pandemic that is happening can be a threat to the essential resources of an individual and thus threaten workplace well-being. It is aligned with the conservation of resources theory (Hobfoll, 1989, 2002) which describes that a person would strive to obtain, maintain, keep, and protect things that are valuable to them. According to the theory, stress occurs when a) essential resources are threatened with loss, b) essential resources are lost, or c) failing to obtain essential resources following significant effort (Hobfoll, 1989, 2002). Thus, it is important to identify the essential resources required by employees especially in dualearner couples who raise children amidst pandemics to achieve workplace well-being. One of the secondary resources that can facilitate well-being attainment is personal characteristics (Rothausen, 2013). In addition, social support can be seen as a resource that provides or facilitates other valuable resources for the individual (Hobfoll, 1989, 2002). Therefore in this study, personal characteristics, core self-evaluation, and spousal support become the essential resources that could be used to predict workplace well-being in dual earner couples which is mediated by work-family conflict.

Previous studies correlated core self-evaluation with well-being about employment, such as burnout and job satisfaction (Hsieh et al., 2019; Wu \& Griffin, 2012). Furthermore, core self-evaluation is often correlated with subjective well-being concept that is hedonicoriented (Liu et al., 2016; Montasem et al., 2013; Rosopa et al., 2016; Sudha \& Shahnawaz, 2013) and psychological well-being which is eudaimonic-oriented (Ding et al., 2020; Gibson \& Hicks, 2018). Specifically, a study that directly links core self-evaluation and workplace well-being has yet to be done. Core self-evaluation is a person's fundamental evaluation of oneself, others, and the world; which is comprised of four aspects namely self-esteem, generalized self-efficacy, locus of control, and emotional stability (Judge et al., 1998). All aspects of core self-evaluation simultaneously reflect individual's positive belief in their own capacity and it motivates them to proactively face stressors so that they can 
deal with the strains that arise (Greaves et al., 2017). A person with high core selfevaluation will assess their own self as having a positive attitude in various situations and as a capable and valuable individual who has control over their life (Judge et al., 2005).

Spousal support is one of the important factors that affect employee well-being (Peeters \& Le Blanc, 2001). Support in the form of advice, understanding, and alikes provided by a spouse (Aycan \& Eskin, 2005) can be distinguished into emotional and instrumental spousal supports (King et al., 1995). Both emotional and instrumental supports can strengthen employee well-being (Irak et al., 2020; Karapinar et al., 2019; Rasool et al., 2019).

The impact of changes during the pandemic period presents new challenges to dualearner couples to be able to decide the boundary between family and work which demands several transitions altogether (Restubog et al., 2020). Goode (1960) explained that overlap in fulfilling several roles at the same time often triggers role strain. Work to family conflict (WFC) is a conflict between roles where demands, time spent, and strains formed due to work issues can affect the responsibilities related to the family (Netemeyer et al., 1996). Core self-evaluation influences work to family conflict that life satisfaction and individual's job will be affected as well (Boyar \& Mosley, 2007).

For countries with Eastern culture, harmony and social values significantly affect relationships within the family and thus social support, especially spousal support, is important (Karapinar et al., 2019). A study by Zhang and Ma (2020) showed that amidst Covid-19 pandemic, respondents experienced an increase in support and felt more caring towards family members. According to buffering hypothesis (Cohen \& Wills, 1985), Covid-19 pandemic becomes a potential event that triggers, where individual assessment towards this event would lead to psychological response or adaptive behavior that affects their well-being and is influenced by social support. Researchers assumed that individuals with high spousal support would be protected from the negative effects of work to family conflict so that they can achieve better well-being.

This study could describe the essential resources and mechanisms to achieve workplace well-being, particularly in dual-earner couples with children in the current pandemic era. The findings could become considerations for organizations in taking strategic steps to formulate policy for dual-earner couples with children so they can maintain productivity during the pandemic. Moreover, this study can contribute to enriching the discourse of well-being within the context of the organization as well as about dual-earner couples in Indonesia during such a trying period. Based on that, researchers propose several hypotheses: 1) there is a direct correlation between core selfevaluation and workplace well-being, 2) there is a direct correlation between spousal support and workplace well-being, 3) work to family conflict mediates the correlation between core self-evaluation and workplace well-being, and 4) work to family conflict mediates correlation between spousal support and workplace well-being. 


\section{Method}

This study was a quantitative study with a correlational design. The sampling technique used was non-probability sampling, specifically accidental sampling. Researchers utilized this sampling technique because the size of the study population was not precisely known and consideration of ease to find respondents participants whilst still considering the representation of respondents based on the specific criteria. The study involved 200 participants with the following characteristics: dual-earner couples who worked full-time and had at least one child aged under 13 years old in the Jakarta Metropolitan area (Jabodetabek). The decision to include parents with children aged 0 to 13 years old was based on the demand of time and energy from parents which is so high in a family with an infant to elementary school children, and thus the possibilities to be exposed to higher psychological stress (Lopata, 1966; Barnett, 1993; in Aycan \& Eskin, 2005).

\section{Research instruments}

There were four research variables in the present study, namely: workplace well-being as the dependent variable, core self-evaluation and spousal support as independent variables, and work to family conflict as mediator. This study tested the role of mediator on the two independent variables in predicting the dependent variable. It utilized several measurements, namely: a) Employee Well-being Scale (EWB) developed by Zheng et al. (2015) to measure employee well-being, specifically in the workplace well-being (WWB) dimension, using 6 items with Cronbach's alpha coefficient $=0.87$; b) Core Self-Evaluation Scale (CSES) developed by Judge et al. (2003) to measure core self-evaluation using 12 items with Cronbach's alpha coefficient $=0.84 ;$ c) Work Family Conflict Scale (WFCS) developed by Netemeyer et al. (1996) to measure work to family conflict using 5 items with Cronbach's alpha coefficient $=0.88 ; 4)$ Family Support Inventory (FSI) developed by King et al. (1995) to measure spousal support using 44 items reported to have Cronbach's alpha coefficients for emotional support scale $=0.97$ and instrumental support scale $=0.93$. All of the measurements used a 6-point Likert scale where 1 was for "Strongly Disagree" and 6 for "Strongly Agree". The measurements were adapted to the Indonesian language following the guideline of cross-cultural adaptation by Beaton et al. (2000): 1) initial translation; 2) translation synthesis; 3) back-translation to the original language; 4) review from the expert committee; and 5) pilot study to 28 respondents. After undergoing scale adaption and considering item factor loading in the pilot study, researchers selected 10 items from CSES and 39 items from FSI.

\section{Data analysis}

Researchers conducted descriptive analysis and assumption tests using SPSS 24.0 version and measurement model testing with confirmatory factor analysis using Lisrel 8.80 
version. Hypothesis testing was done using mediator analysis with two predictors using MPlus 7.0 version.

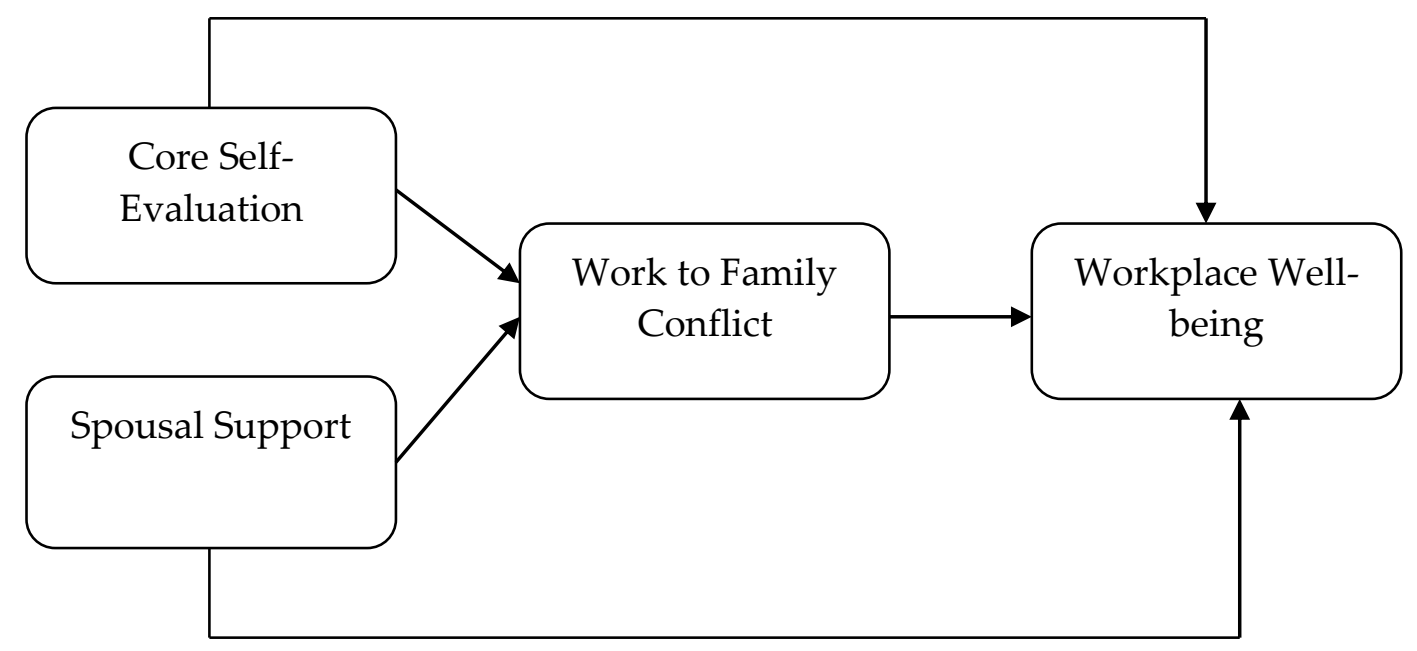

Figure 1. Conceptual model

\section{Result}

Model testing using confirmatory factor analysis was conducted on the four research variables. Workplace well-being, core self-evaluation, and work to family conflict are unidimensional variables; thus measured with 6-item, 10-item, and 5-item scales. Then, the model testing for spousal support consists was first done to test spousal emotional support (27 items) and spousal instrumental support (12 items). According to the analysis done to core self-evaluation, work to family conflict, and spousal support some items should be eliminated as they had low factor loading. There were item reductions in several variables for further analysis and the addition of error covariance for inter-item measurement of similar construct thus the fit indices of the revised measurement model became satisfactory. The measurement model was determined to fit to several indicators suggested by Meyers et al. (2005) and Vieira (2011). For core self-evaluation variable, three items were eliminated $(\mathrm{RMSEA}=0.06, \mathrm{SRMR}=0.04, \mathrm{CFI}=0.99, \mathrm{IFI}=0.99, \mathrm{NFI}=0.97, \mathrm{RFI}=$ 0.95). For work to family conflict, one item was eliminated (RMSEA $=0.08$, SRMR $=0.02$, $\mathrm{CFI}=1.00, \mathrm{IFI}=1.00, \mathrm{NFI}=0.99, \mathrm{RFI}=0.97)$. Meanwhile, for spousal support, each dimension saw one item reduction so that spousal emotional support (SRMR $=0.07, \mathrm{CFI}=$ $0.95, \mathrm{IFI}=0.95, \mathrm{NFI}=0.93, \mathrm{RFI}=0.92)$ and spousal instrumental support fit better (RMSEA $=0.03, \mathrm{SRMR}=0.03, \mathrm{CFI}=1.00, \mathrm{IFI}=1.00, \mathrm{NFI}=0.99, \mathrm{RFI}=0.98)$ fit better. 
Table 1.

Descriptive Statistic, Reliability, and Inter-variable Correlations ( $\mathrm{n}=200)$

\begin{tabular}{|c|c|c|c|c|c|c|c|c|c|c|c|}
\hline \multirow[b]{2}{*}{ No } & \multirow[b]{2}{*}{ Variables } & \multirow[b]{2}{*}{$M$} & \multirow[b]{2}{*}{$S D$} & \multicolumn{8}{|c|}{ Correlation } \\
\hline & & & & 1 & 2 & 3 & 4 & 5 & 6 & 7 & $\varepsilon$ \\
\hline 1 & WWB & 4.5 & 4.1 & $(0.83)$ & & & & & & & \\
\hline 2 & CSE & 4.6 & 4.3 & $.56^{* *}$ & $(0.76)$ & & & & & & \\
\hline 3 & SUPPORT & 4.7 & 22.6 & $.14^{*}$ & $.34^{* *}$ & $(0.93)$ & & & & & \\
\hline 4 & WFC & 3.3 & 4.4 & $-.24^{* *}$ & $-.18^{*}$ & -0.11 & $(0.84)$ & & & & \\
\hline & Respondent's & & & -0.14 & -0.02 & -0.01 & -0.02 & - & & & \\
\hline 5 & Age & 33.5 & 5.6 & & & & & & & & \\
\hline 6 & Child's age & 3.2 & 3.1 & 0.13 & 0.06 & -0.12 & 0.02 & $.20^{* *}$ & - & & \\
\hline 7 & Gender & - & - & -0.003 & $-.15^{*}$ & 0.03 & $.16^{*}$ & $-.26^{* *}$ & 0.03 & - & \\
\hline 8 & Work pattern & - & - & 0.04 & 0.03 & -0.12 & 0.02 & 0.07 & $.15^{*}$ & -0.11 & - \\
\hline
\end{tabular}

aworkplace well-being; ${ }^{\mathrm{b}}$ core self-evaluation; 'spousal support;; work family conflict

Cronbach's alpha coefficient was reported in the brackets alongside the diagonal side of correlational matrix. ${ }^{*} p<.05^{* *} p<.01$

The preliminary analysis; i.e., descriptive statistic, reliability, Product Moment correlational analysis; from the instruments used and presented in Table 1 described the correlation between workplace well-being, core self-evaluation, spousal support, work to family conflict, and the demographic data of respondents. According to Table one, it was found that all of the research variables showed adequate Cronbach's alpha $\alpha>0.70$ (Nunnally \& Bernstein, 1994) which proved that all of the instruments have good reliability.

According to the correlation between demographic data and research variables, it was found that the respondent's age, child's age, and work pattern are not correlated with all of the research variables. Meanwhile, gender is correlated with core self-evaluation and work to family conflict. The distribution of respondents based on gender was $75 \%$ females and $25 \%$ males. The age ranges were 25 to 44 years old ( $94 \%$ of the respondents), 45 to 52 years old ( $5 \%$ of the respondents), and 24 years old ( $1 \%$ of the respondents). During the pandemic, respondents were categorized into several work pattern options: 20\% implemented work from home (WFH), 20\% implemented work from office (WFO), 50\% implemented a combination of WFH and WFO, and 10\% implemented other work patterns. The age of respondents' children was as follows: $54 \% 0$ to 2 years old, $29 \% 3$ to 6 years old, and $17 \%$ within the range of 7 to 12 years old.

According to Table 2, the response distributions of the four variables were dominated by the "high" category. All of the respondents even showed high core self-evaluation amidst the current pandemic situation. In the current pandemic, half of the respondents also perceived high work to family conflict. 
Table 2.

Score Categorization

\begin{tabular}{lcccccc}
\hline \multirow{2}{*}{ Variable } & \multicolumn{2}{c}{ Low } & \multicolumn{2}{c}{ Medium } & \multicolumn{2}{c}{ High } \\
\cline { 2 - 7 } & Frequency & $\%$ & Frequency & $\%$ & Frequency & $\%$ \\
\hline Workplace well-being & 1 & $0.50 \%$ & 75 & $37.50 \%$ & 124 & $62 \%$ \\
Core Self-Evaluation & - & - & - & - & 200 & $100 \%$ \\
Spousal Support & - & - & 34 & $17 \%$ & 166 & $83 \%$ \\
Work to Family Conflict & 23 & $11.50 \%$ & 75 & $37.50 \%$ & 102 & $51 \%$ \\
\hline
\end{tabular}

According to hypothesis testing, there is a direct relationship between core self-evaluation and workplace well-being $(b=-0.54, t=8.75 ; \mathrm{p}<0.05)$ but there is no direct relationship between spousal support and workplace well-being $(b=-0.01, t=-.0 .99 ; p=0.32)$. It can be concluded that the first hypothesis is accepted while the second one is rejected.

Table 3.

Results Regression from Mediation

\begin{tabular}{lcccc}
\hline Paths & $\mathbf{b}$ & SE & $\mathbf{t}$ & $p$ \\
\hline Direct \& Total Effect & & & & \\
CSE $\rightarrow$ WWB & -0.54 & 0.06 & 8.75 & $0.00^{* *}$ \\
Spousal Supp. $\rightarrow$ WWB & -0.01 & 0.01 & -0.99 & 0.32 \\
CSE $\rightarrow$ WFC & -0.17 & 0.08 & -2.20 & $0.03^{*}$ \\
Spousal Supp. $\rightarrow$ WFC & -0.01 & 0.02 & -0.66 & 0.51 \\
WFC $\rightarrow$ WWB & -0.14 & 0.07 & -2.17 & $.03^{*}$ \\
\hline \multicolumn{2}{c}{ Boot b/Boot $\boldsymbol{\beta}$} & SE & Boot LLCI & Boot ULCI \\
\hline Boostrap result for indirect effect & & & & \\
CSE $\rightarrow$ WFC $\rightarrow$ WWB & 0.02 & 0.02 & 0.005 & 0.061 \\
Supp. $\rightarrow$ WFC $\rightarrow$ WWB & 0.00 & 0.00 & -0.002 & 0.007 \\
${ }^{*} p<.05{ }^{* *} p<.01$ & & & &
\end{tabular}

Based on the mediator analysis of two independent variables, it was found that workplace well-being can only be predicted by core self-evaluation mediated by work to family conflict. As seen in Table 3, core self-evaluation has negative effect on work to family conflict $(b=-0.17, t=-2.20 ; \mathrm{p}<0.05)$ and work to family conflict has negative effect on workplace well-being $(\mathrm{b}=-0.14, \mathrm{t}=-2.17 ; \mathrm{p}<0.05)$. The researchers used bootstrapping to test the significance of the non-direct effect from work to family conflict (Hayes, 2013). Using 5000 bootstrapping samples with a 95\% confidence interval, the indirect effect from work to family conflict in the relationship between core self-evaluation and workplace well-being was found significant $(\beta=0.02, \mathrm{SE}=0.02 ; 95 \% \mathrm{CI}[0.005,0.061])$. However, the indirect effect of work to family conflict in the relationship between spousal support and 
workplace well-being was not found significant $(\beta=0.00, \mathrm{SE}=0.00 ; 95 \% \mathrm{CI}[-0.002,0.007])$. Thus, it can be concluded that the third hypothesis is accepted and the fourth one is rejected.

\section{Discussion}

Hobfoll (1989) defined resources as objects, personal characteristics, conditions, or energy that are valuable for a person or that serve as facilitators to obtain other objects, personal characteristics, conditions, or energy. According to the conservation of resource theory (Hobfoll, 2002) and buffering hypothesis (Cohen \& Wills, 1985), researchers examined the role of mediation by work to family conflict on core self-evaluation and spousal support in predicting workplace well-being among dual-earner couples who have at least one child under 13 years old in the Jakarta Metropolitan area during Covid-19 pandemic. In this study, it was found that core self-evaluation can be a significant essential resource to achieve workplace well-being for dual-earner couples but not spousal support.

In the first hypothesis, there is a significant correlation between core self-evaluation and workplace well-being. This aligned with previous studies that linked core selfevaluation with subjective well-being and emotional fatigue which indirectly affects wellbeing (Greaves et al., 2017; O’Donoghue et al., 2016; Rosopa et al., 2016). An individual with high core self-evaluation are known to have higher life and job satisfaction as well as more sensitive in reading signs of problems, thus having advantages in facing future stress (Greaves et al., 2017; Judge et al., 2005; Judge et al., 2008; Piccolo et al., 2005).

In the third hypothesis, it was proven that work to family conflict mediated the relationship between core self-evaluation and workplace well-being. An individual with high core self-evaluation is known to experience lesser work to family conflict (Boyar \& Mosley, 2007). Someone with high core self-evaluation evaluates their ability to solve issues in a more positive light than a person with low core self-evaluation who assesses such situation as a threat (Judge et al., 2005). Thus, this core self-evaluation can help someone to perform proactive coping, which is a form of anticipation or detection towards possible stressors, and act first to prevent or minimalize the effect (Aspinwall \& Taylor, 1997).

Aligned with buffering hypothesis (Cohen \& Wills, 1995) and the conservation of resource theory (Hobfoll, 2002), in the present study, core self-evaluation had a role in reducing the negative effect of work to family conflict that can influence an individual's workplace well-being. Judge et al. (1998) explained that there are two mediation mechanisms in core self-evaluation, situation judgment, and action. In the present study, core self-evaluation drove someone to take action and manage work to family conflict more effectively to achieve better workplace well-being. A person with higher core selfevaluation will perceive the dual roles in their life more positively; as something that is not too demanding, not conflicting with each other, and tend to provide more 
opportunities for evaluation (Westring \& Ryan, 2010). Therefore, dual-earner couples with higher self-evaluation can integrate job roles and family roles, and able to manage work to family conflict better (Karatepe \& Azar, 2013).

A previous study showed that work to family conflict is a mediator between social support, namely supervisor support and family support, and the output of well-being did not show consistent results (Blanch \& Aluja, 2012). Social support can function as a supporting variable in several conditions and it is necessary to link the source of support with the direction of conflict or disturbance (O'Driscoll et al., 2004). Spousal support is expected to be more significant in influencing the family to work conflict, while support from supervisor and coworker is more relevant to work to family conflict (Aycan \& Eskin, 2005; Byron, 2005; Drummond et al., 2017). This is further reinforced by findings from Aryee et al. (1999) and Burkee and Greenglass (1999) which showed that spousal support does not affect work to family conflict but can lower the effect of the family to work conflict. Those research findings can explain the insignificance in the relationship between spousal support and workplace well-being through work to family conflict. The finding in the present study provides an overview that spousal support in work to family conflict is not as relevant compared to previous findings during the pandemic situation.

One of the limitations in this study was not measuring the two-way conflict between work and family comprehensively and only focused on measuring work to family conflict. In a meta-analysis by Byron (2005), the directions of conflict between work and family domains, as well as the sources of support received by a person have their own specifications. Additionally, the uneven distribution of demographic data such as age and gender needs to be taken into consideration as they are found to have an impact on wellbeing research in dual-earner couples. (de Wet et al., 2012; Drummond et al., 2017).

\section{Conclusion}

The conclusion that can be drawn from this study is that core self-evaluation can predict work to family conflict in workplace well-being for dual-earner couples who have children under 13 years old amidst the ongoing pandemic situation. On the other hand, spousal support's role was found to be unable to predict well-being, directly or mediated by work to family conflict. Thus, it is necessary for dual-earner couples with young children to have a better core self-evaluation so that they can tone down the negative effects from pressures of strains related to work and family, as it can incite work to family conflict and affect workplace well-being.

\section{Suggestion}

According to the limitation of the present study, it is suggested that future replications of this study should consider several issues. Future studies can measure both work to family conflict and family to work conflict. In addition, it is necessary to include other sources of 
support such as spousal support, supervisor support, and co-worker support in predicting workplace well-being. The demographical factors of the participants, such as age and number of children, also need to be analyzed.

For human resource practitioners and government, this study's finding can be a basis to formulate policy and development programs for married employees with children during the pandemic. Furthermore, the company can develop employee development programs, such as counseling and training that focus on the aspects of core self-evaluation namely self-esteem, generalized self-efficacy, locus of control, and emotional stability to achieve workplace well-being.

\section{References}

Aryee, S., Luk, V., Leung, A., \& Lo, S. (1999). Role Stressors, Interrole Conflict, and WellBeing: The Moderating Influence of Spousal Support and Coping Behaviors among Employed Parents in Hong Kong. Journal of Vocational Behavior, 54(2), 259-278. https://doi.org/10.1006/jvbe.1998.1667

Aspinwall, L. G., \& Taylor, S. E. (1997). A stitch in time: Self-regulation and proactive coping. Psychological Bulletin. https://doi.org/10.1037/0033-2909.121.3.417

Aycan, Z., \& Eskin, M. (2005). Relative contributions of childcare, spousal support, and organizational support in reducing work-family conflict for men and women: The case of Turkey. Sex Roles, 53(7-8), 453-471. https://doi.org/10.1007/s11199-005-7134-8

Baruch, Y. (2000). Teleworking : benefits and pitfalls as perceived by professionals and managers. 34-49.

Beaton, D. E., Bombardier, C., Guillemin, F., \& Ferraz, M. B. (2000). Guidelines for the Process of Cross-Cultural Adaptation of Self-Report Measures. Spine, 25(24), 31863191. https://doi.org/10.1097/00007632-200012150-00014

Blanch, A., \& Aluja, A. (2012). Social support (family and supervisor), work-family conflict, and burnout: Sex differences. Human Relations, 65(7), 811-833. https://doi.org/10.1177/0018726712440471

Boyar, S. L., \& Mosley, D. C. (2007). The relationship between core self-evaluations and work and family satisfaction: The mediating role of work-family conflict and facilitation. Journal of Vocational Behavior, 71(2), 265-281. https://doi.org/10.1016/j.jvb.2007.06.001

Burke, R. J., \& Greenglass, E. R. (1999). Work-family conflict, spouse support, and nursing staff well-being during organizational restructuring. Journal of Occupational Health Psychology, 4(4), 327-336. https://doi.org/10.1037/1076-8998.4.4.327

Byron, K. (2005). A meta-analytic review of work-family conflict and its antecedents. Journal of Vocational Behavior, 67(2), 169-198. https://doi.org/10.1016/j.jvb.2004.08.009

Cohen, S., \& Wills, T. A. (1985). Stress, social support, and the buffering hypothesis. Psychological Bulletin, 98(2), 310-357. https://doi.org/10.1037/0033-2909.98.2.310 
de Wet, W., van Zittert, P., Koekemoer, E., \& Treurnich, E. (2012). Differences in the Wellbeing of Dual-earner Parents with Young Children. South African Review of Sociology, 43(3), 106-128. https://doi.org/10.1080/21528586.2012.727552

Deci, E. L., \& Ryan, R. M. (2008). Hedonia, eudaimonia, and well-being: An introduction. Journal of Happiness Studies, 9(1), 1-11. https://doi.org/10.1007/s10902-006-9018-1

Ding, H., Yu, E., \& Li, Y. (2020). Transformational leadership and core self-evaluation: The roles of psychological well-being and supervisor-subordinate guanxi. Journal of Psychology in Africa, 30(3), 236-242. https://doi.org/10.1080/14330237.2020.1767934

Drummond, S., O’Driscoll, M. P., Brough, P., Kalliath, T., Siu, O. L., Timms, C., ... Lo, D. (2017). The relationship of social support with well-being outcomes via work-family conflict: Moderating effects of gender, dependants and nationality. Human Relations, 70(5), 544-565. https://doi.org/10.1177/0018726716662696

Fisher, C. D. (2014). Conceptualizing and Measuring Wellbeing at Work. Wellbeing, III, 125. https://doi.org/10.1002/9781118539415.wbwell018

Gibson, A., \& Hicks, R. (2018). Psychological Capital and Core Self-Evaluations in the Workplace: Impacts on Well-Being. International Journal of Psychological Studies, 10(2), 15. https://doi.org/10.5539/ijps.v10n2p15

Goode, W. J. (1960). A Theory of Role Strain. American Sociological Review, 25(4), 483. https://doi.org/10.2307/2092933

Greaves, C. E., Parker, S. L., Zacher, H., \& Jimmieson, N. L. (2017). Working mothers' emotional exhaustion from work and care: The role of core self-evaluations, mental health, and control. Work and Stress, 31(2), 164-181. https://doi.org/10.1080/02678373.2017.1303760

Hayes, A. F. (2013). Introduction to Mediation, Moderation, and Conditional Process Analysis, Second Edition: A Regression-Based Approach. In The Guilford Press. New York.

Hobfoll, S. E. (1989). Conservation of Resources: A New Attempt at Conceptualizing Stress. American Psychologist, 44(3), 513-524. https://doi.org/10.1037/0003066X.44.3.513

Hobfoll, S. E. (2002). Social and Psychological Resources and Adaptation. Review of General Psychology, 6(4), 307-324. https://doi.org/10.1037/1089-2680.6.4.307

Hsieh, H. H., Wang, Y. C., \& Huang, J. T. (2019). Core self-evaluations, perceived organizational support, and work-related well-being: Testing a moderated mediation model. Personnel Review, 48(3), 659-671. https://doi.org/10.1108/PR-04-2018-0128

Irak, D., Kalkışım, K., \& Yıldırım, M. (2020). Emotional Support Makes the Difference: Work-Family Conflict and Employment Related Guilt Among Employed Mothers. Sex Roles, 82(1-2), 53-65. https://doi.org/10.1007/s11199-019-01035-x

Judge, T. A., Erez, A., Bono, J. E., \& Locke, E. A. (2005). Core self-evaluations and job and life satisfaction: The role of self-concordance and goal attainment. Journal of Applied Psychology, 90(2), 257-268. https://doi.org/10.1037/0021-9010.90.2.257 
Judge, T. A., Erez, A., Bono, J. E., \& Thoresen, C. J. (2003). The core self-evaluations scale: Development of a measure. Personnel Psychology, 56(2), 303-331. https://doi.org/10.1111/j.1744-6570.2003.tb00152.x

Judge, T. A., Locke, E. A., Durham, C. C., \& Kluger, A. N. (1998). Dispositional effects on job and life satisfaction: The role of core evaluations. Journal of Applied Psychology, 83(1), 17-34. https://doi.org/10.1037/0021-9010.83.1.17

Kammeyer-Mueller, J. D., Judge, T. A., \& Scott, B. A. (2009). The Role of Core SelfEvaluations in the Coping Process. Journal of Applied Psychology. https://doi.org/10.1037/a0013214

Karapinar, P., Camgoz, S., \& Ekmekci, O. (2019). Employee Wellbeing, Workaholism, Work-Family Conflict and Instrumental Spousal Support: A Moderated Mediation Model. Journal of Happiness Studies, (1806251104). https://doi.org/10.1007/s10902-01900191-x

Karatepe, O. M., \& Azar, A. K. (2013). The Effects of Work-Family Conflict and Facilitation on Turnover Intentions: The Moderating Role of Core Self-Evaluations. International Journal of Hospitality and Tourism Administration, 14(3), 255-281. https://doi.org/10.1080/15256480.2013.809987

King, L. a, Mattimore, L. K., King, D. W., Adams, G. a, Journal, S., May, N., \& King, L. a. (1995). Family Support Inventory for Workers: A New Measure of Perceived Social Support from Family Members Stable URL: http://www.jstor.org/stable/2488511 REFERENCES Linked references are available on JSTOR for this article: You may need to $\log$ in to JSTOR to. Journal of Organizational Behavior, 16(3), 235-258.

Liu, W., Li, Z., Ling, Y., \& Cai, T. (2016). Core self-evaluations and coping styles as mediators between social support and well-being. Personality and Individual Differences, 88, 35-39. https://doi.org/10.1016/j.paid.2015.08.044

Lunn, P., Belton, C., Timmons, S., \& Robertson, D. (2020). Help Fight the Coronavirus. (656). Retrieved from https://www.esri.ie/publications/using-behavioural-science-to-helpfight-the-coronavirus

Maruyama, T., \& Tietze, S. (2012). From anxiety to assurance: concerns and outcomes of telework. Personnel Review, 41(4), 450-469. https://doi.org/10.1108/00483481211229375

Meyers, L. S., Gamst, G., \& Guarino, A. J. (2005). Applied Multivariate Reserach: Design and Interpretation. Thousand Oaks: Sage Publications.

Montasem, A., Brown, S. L., \& Harris, R. (2013). Do core self-evaluations and trait emotional intelligence predict subjective well-being in dental students? Journal of Applied Social Psychology, 43(5), 1097-1103. https://doi.org/10.1111/jasp.12074

Netemeyer, R. G., Boles, J. S., \& McMurrian, R. (1996). Development and validation of work-family conflict and family-work conflict scales. Journal of Applied Psychology, 81(4), 400-410. https://doi.org/10.1037/0021-9010.81.4.400

Nunnally, J. C., \& Bernstein, I. H. (1994). Psychometric Theory (3rd ed.). New York: McGraw-Hill. 
O'Donoghue, A., Conway, E., \& Bosak, J. (2016). Abusive supervision, employee wellbeing and ill-being: The moderating role of core self-evaluations. Research on Emotion in Organizations, 12, 3-34. https://doi.org/10.1108/S1746-979120160000012001

O'Driscoll, M. P., Brough, P., \& Kalliath, T. J. (2004). Work/family conflict, psychological well-being, satisfaction and social support: a longitudinal study in New Zealand. Equal Opportunities International, 23(1/2), 36-56. https://doi.org/10.1108/02610150410787846

Peeters, M. C. W., \& Le Blanc, P. M. (2001). Towards a match between job demands and sources of social support: A study among oncology care providers. European Journal of Work and Organizational Psychology, 10(1), 53-72. https://doi.org/10.1080/13594320042000034

Rasool, I., Zubair, A., \& Anwar, M. (2019). Role of Perceived Self-efficacy and Spousal Support in Psychological Well-being of Female Entrepreneurs. Pakistan Journal of Psychological Research, 34(4), 899-917. https://doi.org/10.33824/PJPR.2019.34.4.48

Restubog, S. L. D., Ocampo, A. C. G., \& Wang, L. (2020). Taking control amidst the chaos: Emotion regulation during the COVID-19 pandemic. Journal of Vocational Behavior, 103440. https://doi.org/10.1016/j.jvb.2020.103440

Rosopa, P. J., Datu, J. A. D., Robertson, S. A., \& Atkinson, T. P. (2016). Core selfevaluations and subjective well-being in the U.S. and the Philippines: The moderating role of self-construal. Scandinavian Journal of Psychology, 57(1), 50-56. https://doi.org/10.1111/sjop.12265

Rothausen, T. J. (2013). Hedonic and Eudaimonic Enjoyment of Job and Fulfillment of Job Purpose. $\quad$ Retrieved from https://ir.stthomas.edu/cgi/viewcontent.cgi?article=1000\&context=ocbmgmtwp

Ryan, R. M., \& Deci, E. L. (2001). On Happiness and Human Potentials: A Review of Research on Hedonic and Eudaimonic Well-Being. Annual Review of Psychology, 52(1), 141-166. https://doi.org/10.1146/annurev.psych.52.1.141

Ryff, C. D. (1989). Happiness is everything, or is it? Explorations on the meaning of psychological well-being. Journal of Personality and Social Psychology, 57(6), 1069-1081. https://doi.org/10.1037/0022-3514.57.6.1069

Santrock, J. W. (2011). Life Span Development (13th ed.). New York: McGraw-Hill.

Sudha, K. S., \& Shahnawaz, M. G. (2013). Core self-evaluation as a correlate of subjective wellbeing among special educators. Journal of the Indian Academy of Applied Psychology, 39(1), 83-89.

Super, D. (2012). Developmental self-concept. Jurnal Manajemen, 20(2), 245-246. https://doi.org/10.24912/jm.v20i2.46

Taha, S., Matheson, K., Cronin, T., \& Anisman, H. (2014). Intolerance of uncertainty, appraisals, coping, and anxiety: The case of the 2009 H1N1 pandemic. British Journal of Health Psychology, 19(3), 592-605. https://doi.org/10.1111/bjhp.12058 
Vieira, A. L. (2011). Interactive LISREL in Practice: Getting Started a SIMPLIS Approach. https://doi.org/10.1007/978-3-642-18044-6

Westring, A. F., \& Ryan, A. M. (2010). Personality and inter-role conflict and enrichment: Investigating the mediating role of support. Human Relations. https://doi.org/10.1177/0018726710371236

Wu, C. H., \& Griffin, M. A. (2012). Longitudinal relationships between core selfevaluations and job satisfaction. Journal of Applied Psychology, 97(2), 331-342. https://doi.org/10.1037/a0025673

Zhang, Y., \& Ma, Z. F. (2020). Impact of the COVID-19 pandemic on mental health and quality of life among local residents in Liaoning Province, China: A cross-sectional study. International Journal of Environmental Research and Public Health, 17(7). https://doi.org/10.3390/ijerph17072381

Zheng, X., Zhu, W., Zhao, H., \& Zhang, C. (2015). Employee well-being in organizations: Theoretical model, scale development, and cross-cultural validation. Journal of Organizational Behavior, 36(5), 621-644. https://doi.org/10.1002/job.1990 